\title{
SUSCETIBILIDADE DE CERCAS-VIVAS, QUEBRA-VENTOS E PLANTAS INVASORAS AO VÍRUS DA LEPROSE E SUA TRANSMISSÃO PARA LARANJEIRAS POR Brevipalpus phoenicis (GEIJSKES) (ACARI: TENUIPALPIDAE) ${ }^{1}$
}

\author{
OZANA MARIA DE ANDRADE MAIA² \& CARLOS AMADEU LEITE DE OLIVEIRA ${ }^{3}$
}

\begin{abstract}
RESUMO - Objetivou-se avaliar a potencialidade de algumas plantas freqüentes em pomares cítricos de hospedar o vírus da leprose, transmitido por Brevipalpus phoenicis (Geijskes). Foram utilizadas as seguintes plantas: Hibiscus sp. L., Malvaviscus mollis DC., Grevillea robusta A. Cunn., Mimosa caesalpiniaefolia Benth., Bixa orellana L., Commelina benghalensis L., Bidens pilosa L., Sida cordifolia L. e Ageratum conyzoides L.. Duas criações-estoque do ácaro foram realizadas, sendo uma sobre frutos com sintomas de leprose e outra sobre frutos sem sintomas. De cada planta hospedeira do ácaro, escolheram-se duas folhas, delimitando-se na face inferior de cada planta uma área, que recebeu ácaros criados sobre frutos com lesões de leprose, que aí permaneceram durante sete dias. Os ácaros foram em seguida transferidos para mudas cítricas das variedades Natal e Valência e mantidos em casa de vegetação. As folhas das diferentes espécies vegetais sobre as quais os ácaros estavam anteriormente, foram destacadas e conservadas em placas de Petri, sobre algodão e papel-filtro umedecido. Ácaros criados sobre frutos sem lesões de leprose foram mantidos por três dias sobre essas folhas e, posteriormente, transferidos para novas mudas cítricas, que também foram subseqüentemente mantidas em uma casa de vegetação. Após 60 dias, quantificou-se o número de lesões de leprose nas mudas cítricas. Os resultados evidenciaram que o ácaro não perdeu a capacidade de transmissão do vírus para mudas cítricas após acesso alimentar por sete dias sobre qualquer uma das plantas intermediárias consideradas no estudo. Ácaros provenientes de frutos sem lesões de leprose adquiriram o vírus da leprose e o transmitiram a mudas cítricas quando tiveram acesso alimentar a $C$. benghalensis, A. conyzoides, B. pilosa, S. cordifolia e B. orellana, onde, anteriormente, ácaros criados sobre frutos com lesões de leprose permaneceram por sete dias. Estes resultados evidenciam a potencialidade de estas plantas serem depositárias e fonte de transmissão do vírus para plantas cítricas suscetíveis.
\end{abstract}

Termos para indexação: ácaro, plantas hospedeiras, transmissão, Citrus sinensis.

\section{INFECTION IN HEDGEROWS, WINDBREAKS AND WEEDS BY LEPROSIES VIRUS AND ITS TRANSMISSION TO ORANGE TREES BY Brevipalpus phoenicis (Geijskes) (Acari: Tenuipalpidae)}

\begin{abstract}
The objective was to evaluate the potential of some common plants in and around citrus orchards to host the leprosies virus, transmitted by the mite Brevipalpus phoenicis (Geijskes).It was used the following plants: Hibiscus sp. L., Malvaviscus mollis DC., Grevillea robusta A. Cunn., Mimosa caesalpiniaefolia Benth., Bixa orellana L., Commelina benghalensis L., Bidens pilosa L., Sida cordifolia L. and Ageratum conyzoides L.. Two stock colonies of the mite were set up; one on fruits with leprosies symptoms and other on fruits without symptoms. Two leaves were selected from each host plant, on which mites reared on fruits with leprosies lesions, and were confined during seven days. Subsequently, the mites were transferred to citrus seedlings variety Natal and Valencia and taken to a greenhouse. The leaves infested with mites were removed and placed on cotton and filter paper in Petri dishes. Mites reared on fruit without leprosies lesions were allowed to feed on the host plant leaves during three days, and were then transferred to citrus seedlings, which were taken to the greenhouse. After 60 days, the number of lesions on the citrus seedlings was counted. The mites continued to transmit the virus to citrus seedlings, even after seven days of feeding on the host plants. Mites reared on fruit without leprosies lesions, acquired the virus and transmitted it to citrus seedlings when kept on $C$. benghalensis, A. conyzoides, B. pilosa, $S$. cordifolia or $B$. orellana leaves on where mites from leprosies lesions had been previously reared. It was conclude that these plants can be depositories and sources for transmission of leprosies virus to susceptible citrus plants.
\end{abstract}

Index terms: mite, host plants, transmission, Citrus sinensis.

\section{INTRODUÇÃo}

A leprose dos citros, doença virótica cujo agente transmissor no Brasil é o ácaro Brevipalpus phoenicis (Geijskes), é um sério problema para a citricultura e constitui uma das principais doenças da cultura (Rossetti, 2001).

Kitajima et al. (1972) examinaram ao microscópio eletrônico secções ultrafinas de tecidos foliares de diversas variedades de laranjeira e de pomelo que apresentavam lesões de leprose, e observaram nas células do mesófilo, adjacentes ao tecido necrosado, a presença de partículas em formas de bastonetes morfologicamente semelhantes às componentes internas de vírus baciliformes de plantas, além de cloroplastos alterados. Segundo os autores, a doença teria etiologia viral, e essas partículas são vistas somente em tecidos com lesões de leprose e nunca em tecido sem lesões (Kitajima et al., 1972; Colariccio et al., 1995).

A ocorrência de partículas semelhantes a vírus nos tecidos foliares com lesões de leprose, mas não em áreas sadias adjacentes, indica um caráter aparentemente não-sistêmico do vírus, ou seja, de localização restrita à extensão da lesão. Isto amplia de modo considerável a importância do vetor na epidemiologia da doença, uma vez que sua ocorrência é condição fundamental para a disseminação da doença dentro da planta e do pomar (Colariccio et al., 1995).

Chiavegato \& Salibe (1986) relatam que o ácaro B. phoenicis, uma vez infectado, não perde a capacidade de transmitir o vírus da leprose quando transferido de uma folha sadia para outra, pelo menos nos quatro primeiros dias de alimentação. Estes mesmos autores constataram ainda que não é necessário o ácaro alimentar-se numa lesão típica de leprose, bastando apenas alimentar-se em áreas onde, previamente, ácaros virulíferos tenham se alimentado.

B. phoenicis é uma espécie polífaga e tem enorme gama de hospedeiros intermediários, os quais podem manter e/ou incrementar suas populações. Estas plantas podem comportar-se como hospedeiras do vírus, o que representa um risco muito grande para a citricultura por se constituírem em focos de infecção, aumentado sobremaneira a probabilidade de contaminação do ácaro e, conseqüentemente, a disseminação da leprose.

Este trabalho objetivou avaliar algumas plantas hospedeiras intermediárias do ácaro B. phoenicis, utilizadas como cercas-vivas/ quebra-ventos em pomares cítricos, bem como as plantas invasoras

\footnotetext{
(Trabalho 164-2005). Recebido: 13-10-2005. Aceito para publicação: 27-04-2006.

${ }^{2}$ Mestranda do Curso Pós-graduação em Entomologia Agrícola, UNESP, Jaboticabal-SP, e-mail: ozana_maia@yahoo.com.br. Bolsista Capes

${ }^{3}$ Departamento de Fitossanidade, FCAV/UNESP, 14884-900, Jaboticabal - SP, e-mail: amadeu@ fcav.unesp.br
} 
mais freqüentes junto a estes, em se constituírem em potenciais hospedeiras do vírus da leprose.

\section{MATERIAL E MÉTODOS}

Os experimentos foram realizados em casa de vegetação e laboratórios pertencentes ao Departamento de Fitossanidade da Faculdade de Ciências Agrárias e Veterinárias (FCAV/UNESP), Câmpus de Jaboticabal-SP, durante os meses de agosto a novembro de 2001.

Criação-estoque de ácaros virulíferos. A criação de ácaros virulíferos foi realizada de acordo com a metodologia adotada por Chiavegato e Mischan (1987). Esta foi desenvolvida a partir de frutos de laranja (Citrus sinensis L. Osbeck) da variedade Pêra-rio, procedentes de pomares da região de Bebedouro-SP, com alta incidência de sintomas de leprose e altos níveis de infestação de ácaros. Foram utilizados frutos com sintomas de leprose e verrugose, pois, segundo estudos realizados por Albuquerque et al., em 1997, esta última doença torna a superfície rugosa, proporcionando locais de abrigo e postura propícios à infestação do ácaro.

No laboratório, os frutos foram submetidos à máquina de varredura "Modelo Jaboticabal" (Oliveira, 1983), para a retirada de possíveis outros ácaros e insetos.

Os frutos, a seguir, receberam uma fina camada de parafina, deixando-se uma área circular de três cm de diâmetro, sem parafina na parte lateral do fruto, onde havia lesões de verrugose e leprose , assegurando assim condições de contaminação do ácaro com o vírus da leprose.

Para impedir a fuga dos ácaros, as áreas foram delimitadas com uma barreira adesiva de Tanglefoot ${ }^{\oplus}$ ' (composto de mamona, resinas naturais de látex e cera vegetal). Ácaros provenientes de uma criação-estoque paralela foram transferidos para essas áreas, com o auxílio de um pincel de poucos pêlos, sob microscópio estereoscópico.

Os frutos foram dispostos em bandejas plásticas e mantidos em câmara climatizada sob temperatura de $25 \pm 1^{\circ} \mathrm{C}$, umidade relativa de $60 \pm 5 \%$ e fotofase de 14 horas.

A criação-estoque foi revigorada, de tempos em tempos, com ácaros da mesma procedência, e os frutos, em início de deterioração, foram substituídos por novos frutos.

Criação-estoque de ácaros não-virulíferos. A criação de ácaros não-virulíferos foi realizada sobre frutos de laranjeira $(C$. sinensis) (variedade Pêra-rio) coletados em pomares cítricos isentos de sintomas de leprose, entretanto com sintomas de verrugose.

Os frutos foram selecionados e preparados de modo semelhante aos utilizados na criação-estoque dos ácaros virulíferos, utilizando-se de frutos com sintomas de verrugose, porém sem sintomas de leprose. O início da criação deu-se a partir de ovos de $B$. phoenicis obtidos de outra colônia mantida em laboratório, pois, segundo Chiavegato et al. (1997), não ocorre transmissibilidade transovariana do patógeno, o que assegura uma população isenta de vírus.

Os procedimentos de manutenção da colônia foram, neste caso, os mesmos descritos para a criação-estoque de ácaros virulíferos. Tanto no caso dos ácaros virulíferos quanto no dos não-virulíferos, os frutos foram dispostos em bandejas plásticas e mantidos em câmara climatizada sob temperatura de $25 \pm 1{ }^{\circ} \mathrm{C}$, umidade relativa de $60 \pm 5 \%$ e fotofase de 14 horas. As colônias foram mantidas em câmaras separadas, com o objetivo de evitar a migração entre as criações.

Com o propósito de se certificar da isenção do vírus na criação-estoque, antes de iniciar o experimento, 20 ácaros adultos foram tomados ao acaso na colônia e transferidos para uma muda de cada variedade (Natal e Valência). Os ácaros foram deixados sobre estas plantas por um período de 60 dias (tempo suficiente para manifestação de sintomas de leprose), caso os mesmos estivessem infectados.

Ensaio em laboratório e casa de vegetação: $O$ ensaio foi delineado estatisticamente em blocos ao acaso, com 10 tratamentos repetidos em quatro blocos, sendo cada unidade experimental constituída de uma planta. Os tratamentos foram constituídos das seguintes plantas hospedeiras intermediárias do ácaro, referidas neste trabalho como "plantas hospedeiras intermediárias": Hibiscus sp. L. (hibisco), Malvaviscus mollis DC. (malvavisco), Grevillea robusta A. Cunn. (grevílea), Mimosa caesalpiniaefolia Benth. (sansão-docampo), Bixa orellana L. (urucum), utilizadas como cercas-vivas/ quebra-ventos e as plantas invasoras, Commelina benghalensis L. (trapoeraba), Bidens pilosa L. (picão-preto), Sida cordifolia L. (guanxuma) e Ageratum conyzoides L. (mentrasto).

Como planta-padrão, utilizou-se $C$. sinensis (laranjeira) (variedade Pêra-rio). Com exceção da trapoeraba, as demais plantas invasoras testadas (picão-preto, guanxuma e mentrasto) são citadas como hospedeiras do ácaro em diversas regiões do Estado de São Paulo (Trindade \& Chiavegato, 1994).

As plantas hospedeiras intermediárias foram devidamente formadas no Horto Florestal da FCAV/UNESP, em condição de ripado: hibisco, malvavisco, grevílea e trapoeraba foram obtidas a partir de estaquia, e as demais plantas, através de semeadura.

Para facilitar o manuseio, antes de serem transplantadas para vasos com capacidade de 5 litros, foram podadas, deixando-se 4 folhas/ planta. Colocou-se uma planta por saco plástico contendo partes iguais de terra, areia e esterco curtido. Posteriormente, estas plantas foram transplantadas para vasos, mantendo a mesma relação solo/ matéria orgânica na composição do substrato.

Em seguida, escolheram-se duas folhas recém-formadas de cada espécie que foram limpas com o auxílio de um pincel e algodão umedecido em água, com o objetivo de retirar qualquer inseto ou ácaro que estivesse sobre elas.

$\mathrm{Na}$ face inferior de cada uma destas folhas, demarcou-se uma área de aproximadamente $2,5 \mathrm{~cm}$ de diâmetro, com a mesma substância adesiva utilizada na criação de ácaros (Tanglefoot $\left.{ }^{\circledR}\right)$. O tamanho da área foi determinado de acordo com a espécie que apresentava as menores folhas (picão-preto), de forma que o tamanho fosse aproximadamente o mesmo para todas as plantas hospedeiras intermediárias. As exceções foram as plantas de sansão-do-campo e laranjeira, em que os ácaros foram transferidos para dois ramos, uma vez que era muito grande a fuga dos ácaros quando colocados sobre estas folhas.

Com o auxílio de um pincel de poucos pêlos e sob microscópio estereoscópico, foi transferido para cada área delimitada de cada folha (ou ramo) um número de ácaros (procedentes da criaçãoestoque de ácaros criados sobre frutos com lesões de leprose), como indicado a seguir: (trapoeraba (35), picão-preto (38), guanxuma (36), mentrasto (33), sansão-do-campo (49), urucum (32), hibisco (29), malvavisco (29), grevílea (35) e laranjeira (52)).

Dessa forma, foi possível a recuperação de, no mínimo, 20 ácaros de cada folha ou ramo, após sete dias de acesso alimentar sobre as mesmas.

Ao final deste período, os 20 ácaros mais ativos encontrados sobre as áreas delimitadas foram recuperados e transferidos também, com o auxílio de um pincel de poucos pêlos (sob microscópio estereoscópico), para mudas cítricas no estágio usualmente utilizado para plantio (variedades Valência e Natal).

Logo após a transferência dos ácaros, as folhas das plantas hospedeiras intermediárias em que os ácaros haviam permanecido, foram destacadas das plantas com pinça de ponta fina e transferidas para placas de Petri contendo papel-filtro sobre uma fina camada de algodão hidrófilo umedecido com água. Sob microscópio estereoscópico, as folhas foram examinadas minuciosamente, a fim de se certificar da total ausência de ácaros remanescentes da transferência anterior.

Dada à dificuldade de as folhas de grevílea manterem-se túrgidas, e devido à preferência do ácaro pelos ramos de sansão-docampo e laranjeira, estas três plantas tiveram seus ramos destacados e mantidos em tubos de ensaio contendo algodão hidrófilo saturado 
de água.

Para avaliar se os ácaros não-virulíferos se infectam ao se alimentarem em áreas foliares que anteriormente tenham servido de alimentação aos ácaros virulíferos, oriundos da criação-estoque de ácaros criados sobre frutos sem lesões de leprose, um número suficiente de ácaros para assegurar a recuperação de, no mínimo, 20 ácaros/área, após três dias de acesso alimentar sobre estas folhas, foi transferido para as áreas delimitadas em cada espécie vegetal.

Findo esse período, os 20 ácaros mais ativos presentes sobre cada área foram recuperados e transferidos para quatro mudas cítricas sadias (variedades Valência e Natal). As mudas cítricas contendo os ácaros também foram mantidas em casa de vegetação.

A umidade relativa do ar e temperaturas médias foram registradas através de um termoigrógrafo (Marca Thies) durante os meses de agosto, setembro, outubro e novembro, que correspondem ao período de condução do experimento na casa de vegetação: $\mathrm{UR}=62 \% \pm 11 \%$ e $\mathrm{T}=35 \pm 2{ }^{\circ} \mathrm{C} ; \mathrm{UR}=59 \% \pm 11 \%$ e $\mathrm{T}=35 \pm 3^{\circ} \mathrm{C}$; $\mathrm{UR}=68 \% \pm 16 \%$ e $\mathrm{T}=24 \pm 3^{\circ} \mathrm{C} ; \mathrm{UR}=68 \% \pm 16 \%$ e $\mathrm{T}=24 \pm 3^{\circ} \mathrm{C}$, respectivamente, aos referidos meses.

Decorridos 60 dias, avaliou-se a ocorrência de sintomas de leprose nas mudas cítricas.

Quantificou-se o número de lesões de leprose em folhas, ramos e caule nas mudas cítricas. Os dados relativos às contagens de lesões de leprose foram transformados em $\sqrt{x+0,5}$, com o objetivo de normalização dos resultados para serem submetidas ao teste $\mathrm{F}$, e as médias, comparadas pelo teste Tukey, a 5\% de probabilidade.

\section{RESULTADOS E DISCUSSÃO}

Capacidade de B. phoenicis em transmitir o vírus da leprose, após permanecer durante sete dias sobre plantas hospedeiras intermediárias. O número de lesões de leprose nas mudas cítricas da variedade Natal foi maior do que em mudas da variedade Valência (Tabela 1).

Nenhuma lesão de leprose foi verificada em mudas cítricas da variedade Valência quando estas receberam ácaros provenientes de malvavisco e grevílea, enquanto pouquíssimas lesões foram verificadas em mudas cítricas desta mesma variedade quando esta recebeu ácaros procedentes das plantas de hibisco.

Não houve diferença significativa entre as lesões apresentadas entre as variedades Valência e Natal, quando estas receberam ácaros que se alimentaram previamente em picão-preto, guanxuma, mentrasto, urucum, malvavisco, grevílea e laranjeira. Todavia, quando as mudas cítricas das duas variedade receberam ácaros de trapoeraba e sansão-do-campo, diferiram significativamente em relação aos outros tratamentos.
Não ocorrem lesões de leprose em mudas cítricas da variedade Natal quando estas receberam ácaros procedentes de guanxuma, mentrasto e sansão-do-campo.

Nas mudas cítricas da variedade Natal, nenhuma diferença foi determinada entre o número de lesões observado quando o hospedeiro intermediário foi trapoeraba, picão-preto, urucum, hibisco, malvavisco, grevílea e laranjeira Pêra-rio, e somente trapoeraba diferiu estatisticamente de guanxuma, mentrasto e sansão-do-campo.

Ao examinar os resultados da análise conjunta do número de lesões, independentemente da variedade cítrica considerada, verificou-se que o número de lesões causadas por ácaros provenientes de laranjeiras (variedade Pêra-rio) não diferiu significativamente de trapoeraba, picão-preto, urucum e hibisco. Ressalta-se, todavia, o fato de que, em nenhuma das plantas testadas, o ácaro perdeu a capacidade de transmitir o vírus, aparecendo sintomas em uma ou outra variedade em estudo.

Entretanto, quando se consideraram apenas as variedades Natal ou Valência, independentemente da planta hospedeira intermediária, o número de lesões não diferiu estatisticamente entre si. As manifestações de sintomas nestas variedades também foram observadas por Chiavegato \& Mischan (1987) e Rodrigues (2000), que verificaram serem estas as variedades mais favoráveis ao desenvolvimento do acarino.

Rodrigues (1995) manteve uma população portadora do agente causal da leprose sobre uma planta não-rutácea, Ligustrum lucidum Ait. (ligustre), por 50 dias, período após o qual transferiu os ácaros para plantas de laranjeira (variedade Pêra) e constatou sintomas de leprose, indicando a persistência do agente etiológico na população do ácaro vetor e/ou a multiplicação na planta não-cítrica. Todavia, o não-aparecimento de lesões em ambas as variedades pode ser devido à baixa capacidade de transmissão do acarino, fato esse observado por Chagas et al. (1983) e Rodrigues (1995), que constataram uma eficiência de transmissão ao redor de $10 \%$ para ácaros adultos.

Os resultados obtidos neste trabalho confirmaram os observados por Boareto \& Chiavegato (1994), que indicaram que $B$. phoenicis não perde a capacidade de transmitir leprose mesmo após um período de seis dias de alimentação em folhas sadias de laranjeiras e cafeeiros.

Capacidade de ácaros não-virulíferos em transmitir a leprose após acesso alimentar a plantas hospedeiras intermediárias, anteriormente infestadas com ácaros virulíferos.

O número de lesões em mudas cítricas da variedade Valência, infestada com ácaros procedentes de laranjeiras (variedade Pêra-rio), foi mais elevado, diferindo significativamente do número de lesões ocasionadas por ácaros procedentes de sansão-do-campo, hibisco, malvavisco, grevílea, mentrasto e urucum (Tabela 2).

TABELA 1 - Médias ( \pm EPM) de lesões de leprose em folhas e ramos de laranjeiras (variedades Valência e Natal), 60 dias após a transferência de B. phoenicis virulíferos que permaneceram durante sete dias alimentando-se sobre diferentes plantas hospedeiras intermediárias. Jaboticabal-SP, 2001

\begin{tabular}{|c|c|c|c|c|c|c|}
\hline \multirow{3}{*}{$\begin{array}{l}\text { Plantas hospedeiras intermediárias } \\
\text { C. benghalensis (trapoeraba) }\end{array}$} & \multicolumn{4}{|c|}{ Variedade } & \multirow{2}{*}{\multicolumn{2}{|c|}{ Média }} \\
\hline & \multicolumn{2}{|c|}{ Valência } & \multicolumn{2}{|l|}{ Natal } & & \\
\hline & $9,7 \pm 5,19$ & $\mathrm{~b} A B$ & $62,0 \pm 29,11$ & a A & $35,9 \pm 16,88$ & $\mathrm{AB}$ \\
\hline B. pilosa (picão-preto) & $15,3 \pm 3,54$ & a $\mathrm{AB}$ & $18,5 \pm 6,25$ & a $\mathrm{AB}$ & $16,9 \pm 3,38$ & $\mathrm{AB}$ \\
\hline S. cordifolia (guanxuma) & $10,5 \pm 1,94$ & a $\mathrm{AB}$ & $0,0 \pm 0,00$ & a B & $5,2 \pm 1,8$ & $\mathrm{~B}$ \\
\hline A. conyzoides (mentrasto) & $12,5 \pm 7,15$ & a $\mathrm{AB}$ & $0,0 \pm 0,00$ & a B & $6,2 \pm 4,07$ & $\mathrm{~B}$ \\
\hline M.caesalpiniaefolia (sansão-do-campo) & $23,0 \pm 0,71$ & a $\mathrm{AB}$ & $0,0 \pm 0,00$ & b B & $11,5 \pm 4,36$ & $\mathrm{~B}$ \\
\hline B. orellana (urucum) & $9,0 \pm 5,07$ & a AB & $44,2 \pm 44,25$ & $\mathrm{a} A B$ & $26,6 \pm 21,67$ & $\mathrm{AB}$ \\
\hline Hibiscus sp. (hibisco) & $2,2 \pm 0,75$ & b B & $46,0 \pm 34,91$ & a AB & $24,1 \pm 18,16$ & $\mathrm{AB}$ \\
\hline M. mollis (malvavisco) & $0,0 \pm 0,00$ & a B & $9,5 \pm 3,50$ & $\mathrm{a} A B$ & $4,7 \pm 2,42$ & $\mathrm{~B}$ \\
\hline G. robusta (grevílea) & $0,0 \pm 0,00$ & a B & $21,7 \pm 21,75$ & $\mathrm{a} A B$ & $10,9 \pm 10,88$ & $\mathrm{~B}$ \\
\hline C. sinensis (laranjeira var. Pêra -rio) & $63,0 \pm 13,91$ & a A & $36,2 \pm 9,20$ & $\mathrm{a} \mathrm{AB}$ & $49,6 \pm 9,23$ & A \\
\hline MÉDIA & $14,5 \pm 3,21$ & $\mathrm{a}$ & $23,8 \pm 6,86$ & $\mathrm{a}$ & $19,2 \pm 3,80$ & \\
\hline
\end{tabular}

Médias seguidas da mesma letra minúscula na linha e maiúscula na coluna não diferem significativamente entre si, pelo teste de Tukey (P $\geq 0,05$ ). 
TABELA 2 - Médias ( \pm EPM) de lesões leprose em folhas e ramos de laranjeiras (variedades Valência e Natal), 60 dias após a infestação com ácaros B. phoenicis inicialmente não-virulíferos com acesso alimentar de três dias sobre folhas de plantas hospedeiras intermediárias (anteriormente infestadas com ácaros virulíferos). Jaboticabal-SP, 2001.

\begin{tabular}{|c|c|c|c|c|c|c|}
\hline \multirow{3}{*}{$\begin{array}{l}\text { Plantas hospedeiras intermediárias } \\
\text { C. Benghalensis (trapoeraba) }\end{array}$} & \multicolumn{4}{|c|}{ Variedade } & \multirow{2}{*}{\multicolumn{2}{|c|}{ Média }} \\
\hline & \multicolumn{2}{|c|}{ Valência } & \multicolumn{2}{|c|}{ Natal } & & \\
\hline & $9,2 \pm 3,88$ & a $\mathrm{ABC}$ & $11,7 \pm 5,38$ & a B & $10,5 \pm 3,11$ & $\mathrm{~B}$ \\
\hline$B$. pilosa (picão-preto) & $9,2 \pm 6,66$ & a ABC & $1,2 \pm 1,25$ & a B & $5,2 \pm 3,48$ & $\mathrm{BC}$ \\
\hline S. cordifolia (guanxuma) & $18,0 \pm 6,52$ & a $\mathrm{AB}$ & $0,0 \pm 0,00$ & b B & $9,0 \pm 4,55$ & $\mathrm{BC}$ \\
\hline A. conyzoides (mentrasto) & $6,5 \pm 4,09$ & $\mathrm{a} B C$ & $11,0 \pm 4,51$ & $\mathrm{a} A B$ & $8,7 \pm 2,94$ & $\mathrm{BC}$ \\
\hline M.caesalpiniaefolia (sansão-do-campo) & $0,0 \pm 0,00$ & a C & $0,0 \pm 0,00$ & a B & $0,0 \pm 0,00$ & $\mathrm{C}$ \\
\hline B. orellana (urucum) & $5,5 \pm 2,96$ & a BC & $5,5 \pm 2,60$ & a $\mathrm{AB}$ & $5,5 \pm 1,82$ & $\mathrm{BC}$ \\
\hline Hibiscus sp. (hibisco) & $0,0 \pm 0,00$ & $\mathrm{a} \mathrm{C}$ & $0,0 \pm 0,00$ & a B & $0,0 \pm 0,00$ & $\mathrm{C}$ \\
\hline M. mollis (malvavisco) & $0,00 \pm 0,0$ & a C & $0,0 \pm 0,00$ & a B & $0,0 \pm 0,00$ & $\mathrm{C}$ \\
\hline G. robusta (grevílea) & $0,0 \pm 0,00$ & a C & $0,0 \pm 0,00$ & a B & $0,0 \pm 0,00$ & $\mathrm{C}$ \\
\hline C. sinensis (laranjeira var. Pêra -rio) & $28,0 \pm 5,37$ & a A & $26,7 \pm 2,84$ & a A & $27,4 \pm 2,82$ & A \\
\hline MÉDIA & $7,6 \pm 1,78$ & $\bar{a}$ & $5,6 \pm 1,51$ & $\mathrm{a}$ & $6,6 \pm 1,16$ & \\
\hline
\end{tabular}

Médias seguidas da mesma letra minúscula na linha e maiúscula na coluna não diferem significativamente entre si, pelo teste de Tukey (P $\geq 0,05)$.

Nenhuma lesão foi observada quando os ácaros se alimentaram de sansão-do-campo, hibisco, malvavisco e grevílea. Não se observou diferença estatística entre os números de lesões em plantas infestadas com ácaros procedentes de laranjeira Pêra-rio, trapoeraba, picão-preto e guanxuma.

O número de lesões em guanxuma foi semelhante ao encontrado em laranjeiras (variedade Pêra-rio) e superior ao do sansãodo-campo, hibisco, malvavisco e grevílea.

A hipótese de que outras plantas, além das cítricas, possam hospedar o vírus da leprose e que o ácaro nessas plantas possa adquiri-lo e transmiti-lo para os citros, fica evidente quando se analisam os resultados dos tratamentos em trapoeraba, picão-preto, guanxuma, mentrasto e urucum.

O número de lesões de leprose nas mudas cítricas da variedade Valência foi maior do que em mudas da variedade Natal.

Mudas cítricas da variedade Natal, com ácaros procedentes de laranjeiras (variedade Pêra-rio), apresentaram um número de lesões superior significativo, quando comparado às espécies hospedeiras intermediárias: trapoeraba, picão-preto, guanxuma, sansão-do-campo, hibisco, malvavisco e grevílea, que não diferiram entre si; exceto as mudas cítricas que receberam ácaros provenientes de trapoeraba e picão-preto, todas as outras não apresentaram lesões de leprose.

Os números de lesões causadas por ácaros provenientes de mentrasto e urucum foram elevados, entretanto não diferiram significativamente dos acarretados pelos ácaros provenientes de laranjeiras (variedade Pêra-rio)

Pela análise conjunta do número de lesões, independentemente da variedade cítrica (Valência ou Natal), o número de lesões com ácaros procedentes de laranjeiras (variedade Pêra-rio) foi superior ao observado com ácaros provenientes de todas as plantas hospedeiras intermediárias ensaiadas, evidenciando a alta suscetibilidade da laranjeira em relação às demais plantas. Todavia, a constatação de mudas cítricas apresentarem elevados números de lesões, já era esperada. No entanto, o mais relevante é o fato de várias plantas do agroecossistema citrícola, como as cercas-vivas e/ou quebra-ventos e plantas invasoras, serem hospedeiras do vírus, como urucum, trapoeraba, picão-preto, guanxuma e mentrasto, sendo que esta última é considerada muito favorável à criação e manutenção de ácaros predadores.

O número diferenciado de lesões nas variedades cítricas com ácaros procedentes das diferentes plantas utilizadas neste estudo pode estar relacionado a fatores intrínsecos à planta hospedeira intermediária utilizada, à variedade cítrica utilizada (Valência ou Natal), à baixa capacidade de transmissão do ácaro, ao estresse sofrido pelo ácaro em estar sendo manuseado em um período curto, ou até mesmo ao tempo de acesso alimentar (três dias). Chiavegato \& Salibe (1986), no entanto, verificaram que o ácaro adquiriu o agente causal de leprose após ter se alimentado por dois dias em folhas que, previamente, serviram de alimento para ácaros de pomares contaminados durante quatro dias. Rodrigues (1995) observou a presença de partículas semelhantes a vírus em grande abundância no corpo de B. phoenicis, sugerindo que o patógeno seja do tipo circulativo, não só acumulandose, mas também multiplicando-se no corpo do vetor.

As constatações obtidas neste trabalho implicam a adoção de novas estratégias de manejo do ácaro vetor, levando-se em consideração as cercas-vivas e/ou quebra-ventos e as plantas invasoras, com o intuito de se conseguir um controle mais eficaz da leprose na cultura dos citros.

\section{CONCLUSÕES}

Ácaros não-virulíferos criados sobre frutos sem lesões de leprose e alimentados por 3 dias em folhas de trapoeraba, mentrasto, picão-preto, guanxuma e urucum, onde anteriormente ácaros criados sobre frutos com lesões de leprose permaneceram alimentando-se por sete dias, adquiriram o vírus da leprose e o transferiram para mudas cítricas (variedades Valência ou Natal).

Os resultados evidenciam a potencialidade de estas plantas serem depositárias e fonte de transmissão deste vírus para mudas cítricas através de B.phoenicis.

\section{AGRADECIMENTOS}

À Coordenação de Aperfeiçoamento de Pessoal de Nível Superior (CAPES), pela concessão da bolsa de mestrado, e ao Fundo de Defesa da Citricultura (FUNDECITRUS), pelo suporte técnico.

A Reinaldo Aparecido Longo (Laboratório de Acarologia da Faculdade de Ciências Agrárias e Veterinárias (FCAV/UNESP), Câmpus de Jaboticabal-SP).

\section{REFERÊNCIAS}

ALBUQUERQUE, F.A.; OLIVEIRA, C.A.L. DE; BARRETO, M. Estudos da relação entre as incidências de verrugose da laranja-doce e leprose dos citros em frutos de laranja-pêra. Científica, São Paulo, v. 25, p.393-402, 1997.

BOARETO, M.A.C.; CHIAVEGATO, L.G. Transmissão da leprose por ácaros Brevipalpus phoenicis (Geijskes, 1939) (Acari: Tenuipalpidae) temporariamente mantidos em hospedeiros intermediários em condições de laboratório. Científica, São Paulo, v. 22, p. 81-83, 1994.

CHAGAS, C.M.; ROSSETTI, V.; CHIAVEGATO, L.G. Effectiveness of the different life cycle stages of Brevipalpus phoenicis Geijskes in leprosis transmission. In: CONFERENCE OF THE 
INTERNATIONAL ORGANIZATION OF CITRUS VIROLOGISTS, 9., Riverside. Proceedings... 1983. p.211-214.

CHIAVEGATO, L.G.; SALIBE, A.A.Transmissibility of leprosis symptoms by mite Brevipalpus phoenicis citrus. In: CONFERENCEOFTHE INTERNATIONALORGANIZATIONOF CITRUS VIROLOGISTS, 10., 1986, Valência. Abstract... p.136.

CHIAVEGATO, L.G.; MISCHAN, M.M. Comportamento do ácaro Brevipalpus phoenicis (Geijskes, 1939) (Acari: Tenuipalpidae) em frutos de diferentes variedades cítricas. Científica, São Paulo, v.15, p. 17-22, 1987.

CHIAVEGATO, L.G.; PEREIRA, G.M.S.; PAVARINI, R. Avaliação de diferentes fases de desenvolvimento de Brevipalpus phoenicis (Geijskes, 1939) (Acari: Tenuipalpidae) na transmissão da leprose em plantas cítricas. Científica, São Paulo, v. 25, p. 307-315, 1997.

COLARICCIO, A.; LAVISSOLO, O.; CHAGAS, C.M.; GALLETI, S.R.; ROSSETTI, V.; KITAJIMA, E.W. Mechanical transmission and ultrastructural aspects of citrus leprosis virus. Fitopatologia Brasileira, Brasília, v. 20, p. 208-213, 1995.

KITAJIMA, E.W.; MÜLLER, G.W.; COSTA, A.S.; YURI, V.A. Short rod like particles associated with citrus leprosis. Virology, Orlando, v. 50, p. 254-258, 1972.
OLIVEIRA, C. A. L. de. Máquina de varredura de ácaro Modelo Jaboticabal. Anais da Socidade Entomológica do Brasil, Jaboticabal, v.12, p. 299-303, 1983.

RODRIGUES, J.C.V. Leprose dos citros: Cito-histologia, transmissibilidade e relações com o ácaro vetor Brevipalpus phoenicis (Acari: Tenuipalpidae), 1995. 79 f. Dissertação (Mestrado) - Centro de Energia Nuclear na Agricultura, Universidade de São Paulo, Piracicaba, 1995.

RODRIGUES, J.C.V. Relação patógeno-vetor-planta no sistema leprose dos citros, 2000. 168f. (Tese) (Doutorado) -Centro de Energia Nuclear na Agricultura, Universidade de São Paulo, Piracicaba, 2000.

ROSSETTI, V.V. Manual ilustrado de doenças dos citros. Piracicaba: Fealq/Fundecitrus, 2001. 207p.

TRINDADE, M.L.B.; CHIAVEGATO, L.G. Caracterização biológica dos ácaros Brevipalpus obovatus (Donnadieu, 1875), Brevipalpus californicus (Banks, 1904) e Brevipalpus phoenicis (Geijskes, 1939) (Acari: Tenuipalpidae) em variedades cítricas. Laranja, Cordeirópolis, v.11, p. 227-240, 1994. 